\title{
DEVELOPMENT OF A ROUTE GUIDANCE SUPPORT SYSTEM FOR THE VISUALLY IMPAIRED IN RAILWAY STATIONS
}

\author{
JONG-GYU HWANG, KYEONG-HEE KIM \& TAE-KI AHN \\ Korea Railroad Research Institute (KRRI), South Korea
}

\begin{abstract}
It is difficult for a commuter to find a desired path, which can be very complex in the case of navigating an urban railway station where there are several routes. The visually impaired, especially, have more difficulty finding their desired paths or points within a railway station. They have even more difficulty finding available paths, including stairs, to reach a platform where they want to go than the general public do. Therefore, the satisfaction level on mobility for the handicapped, including the visually impaired, when using railway stations is very low, in comparison with that of the general public. In this paper, a route guidance support system is provided that can guide by smart Braille block-based routes in railway stations is proposed, to enhance the mobility satisfaction level of the visually impaired.

Keywords: mobility, blind, Braille, handicapped, visually impaired, route guidance support system, railway station, smart Braille block.
\end{abstract}

\section{INTRODUCTION}

The mobility handicapped form a user group that has temporary or continuous restrictions or inconvenience in movement when using public transportation facilities, due to their behavioural inconvenience. In the case of Korea, the portion of these people has increased remarkably. Thus, inconvenience will also be increased, due to the decline in their cognitive ability to judge, physical conditions, etc., when they make use of the railway stations. Among the mobility handicapped, especially the visually impaired are experiencing inconvenience, because of their blindness or being weak-eyed. Addressing this mobility enhancement for the mobility handicapped, including the visually impaired, the Mobility Enhancement for the Mobility Handicapped Act (abbreviated as MEMH ACT) was enacted in Korea, under the vision of realization of society having traffic welfare become convenient for all [1].

Table 1 shows the result of surveying the utilization satisfaction of the railway station and installation rate prescribed by the MEMH ACT. The satisfaction rate compared to the installation rate is relatively low in all of the railway stations. In particular, it can be seen that the satisfaction rate of railway station utilization for the mobility handicapped is about $10 \%$ lower than that of the general public [2]. It can also be seen that the transportation handicapped feel much inconvenience and difficulty in using public transportation facilities such as railway stations, compared with the general public [4]-[6]. As such, the satisfaction rate is lower than the installation rate of the mobility facility in the railway stations. To overcome these problems, this paper proposes a smart Braille block-based route guidance system in railway stations that can enhance the satisfaction of visually impaired people using the railway stations (Fig. 1).

\section{OVERVIEW OF THE PROPOSED SYSTEM}

The mobility handicapped, according to the MEMH ACT, are defined as people who are experiencing difficulties in moving about while living their lives, such as the visually impaired, deaf, pregnant, elderly, children, infants, etc. Among them, the visually impaired 
Table 1: Installation and satisfaction rate for the railways and other passenger facilities.

\begin{tabular}{|c|l|c|c|c|}
\hline \multirow{2}{*}{ Classification } & \multicolumn{3}{|c|}{ The end of 2017 } \\
\cline { 3 - 5 } & \multirow{2}{*}{$\begin{array}{c}\text { Installation } \\
\text { rate }\end{array}$} & \multicolumn{2}{|c|}{ Satisfaction rate } \\
\cline { 3 - 5 } & Public & $\begin{array}{c}\text { Mobility } \\
\text { handicapped }\end{array}$ \\
\hline \multirow{5}{*}{$\begin{array}{c}\text { Passenger } \\
\text { facility }\end{array}$} & \begin{tabular}{l} 
Passenger car terminal \\
Urban railway and subway \\
\cline { 2 - 5 }
\end{tabular} & 60 & 64 & 56 \\
\cline { 2 - 5 } & Railway station & 89 & 72 & 64 \\
\cline { 2 - 5 } & Airport passenger terminal & 81 & 70 & 63 \\
\cline { 2 - 5 } & Passenger ship terminal & 87 & 66 & 64 \\
\cline { 2 - 5 } & Bus terminal & 53 & 64 & 48 \\
\hline
\end{tabular}
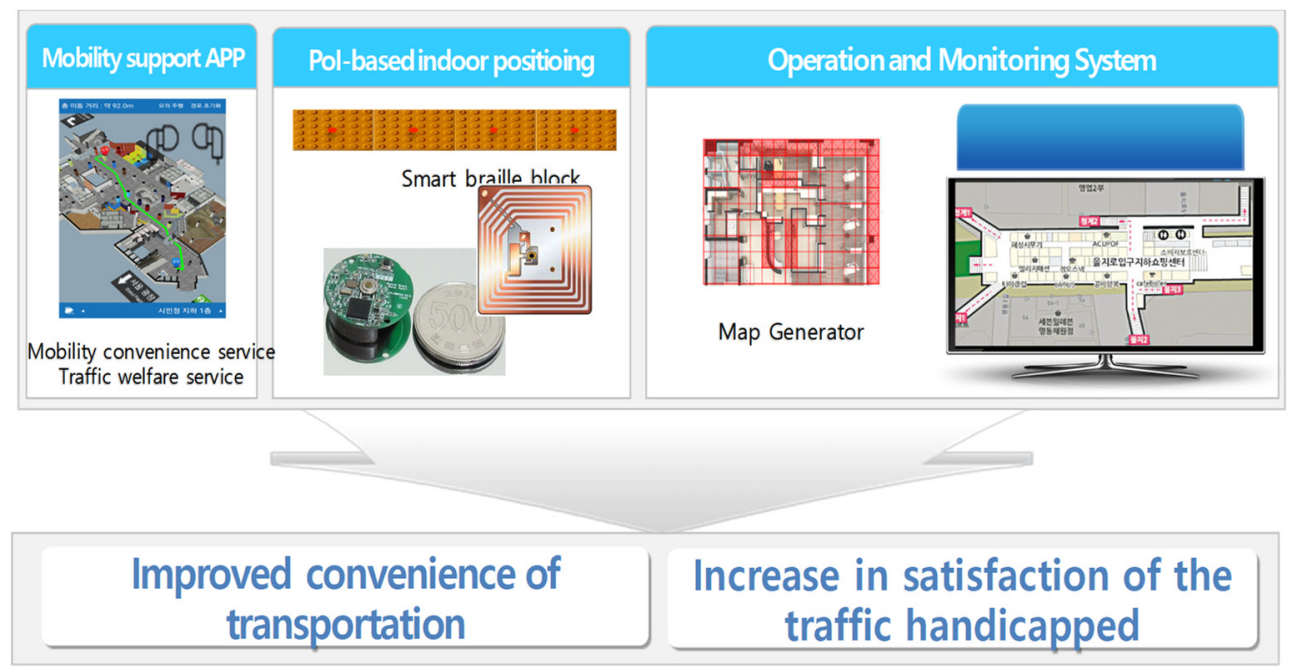

Figure 1: Overview of the proposed mobility-enhancing system.

have many difficulties. Therefore, it is necessary to establish measures to improve the mobility satisfaction of the visually impaired. A Braille block application-based system for supporting the visually impaired is proposed and developed in this paper (Fig. 1) [3].

Average satisfaction of the railway station was 72 points for the general public. On the other hand, the average for mobility handicapped was 63, which means that their dissatisfaction rate is high, and satisfaction rate is low [2]. Traffic disadvantages are being analysed, as they were the most complained-about problem in utilizing the railway stations. In order to improve these rates, an additional installation or improvement is required at station facilities, such as the vertical facilities. These needed changes could be very many and costly, so it is a difficult problem to solve.

The cause providing the most dissatisfaction for the impaired is complaints about facility infrastructure such as stairways, elevators and such, related to the limitations of the informational equipment, when commuters are looking for their destination within railway 
stations. The methodology which can be used to solve this problem using information and communication technology (ICT) was considered in our research. The Braille blocks have been installed at most station floors. We propose a smart Braille block system, with an Internet of Things (IoT) sensor added to it [3], and propose a route guidance system based on this Braille block that can be used through a mobile phone application (APP). Fig. 1 shows the overall concept of the proposed system, while Fig. 2 shows the architecture of this system. It is necessary to provide these services, such as station map-based convenience route guidance services, and location information on facilities for a mobility-supported application system. Also, it would be better if safety information were provided, but providing that safety information will be the subject of further research.

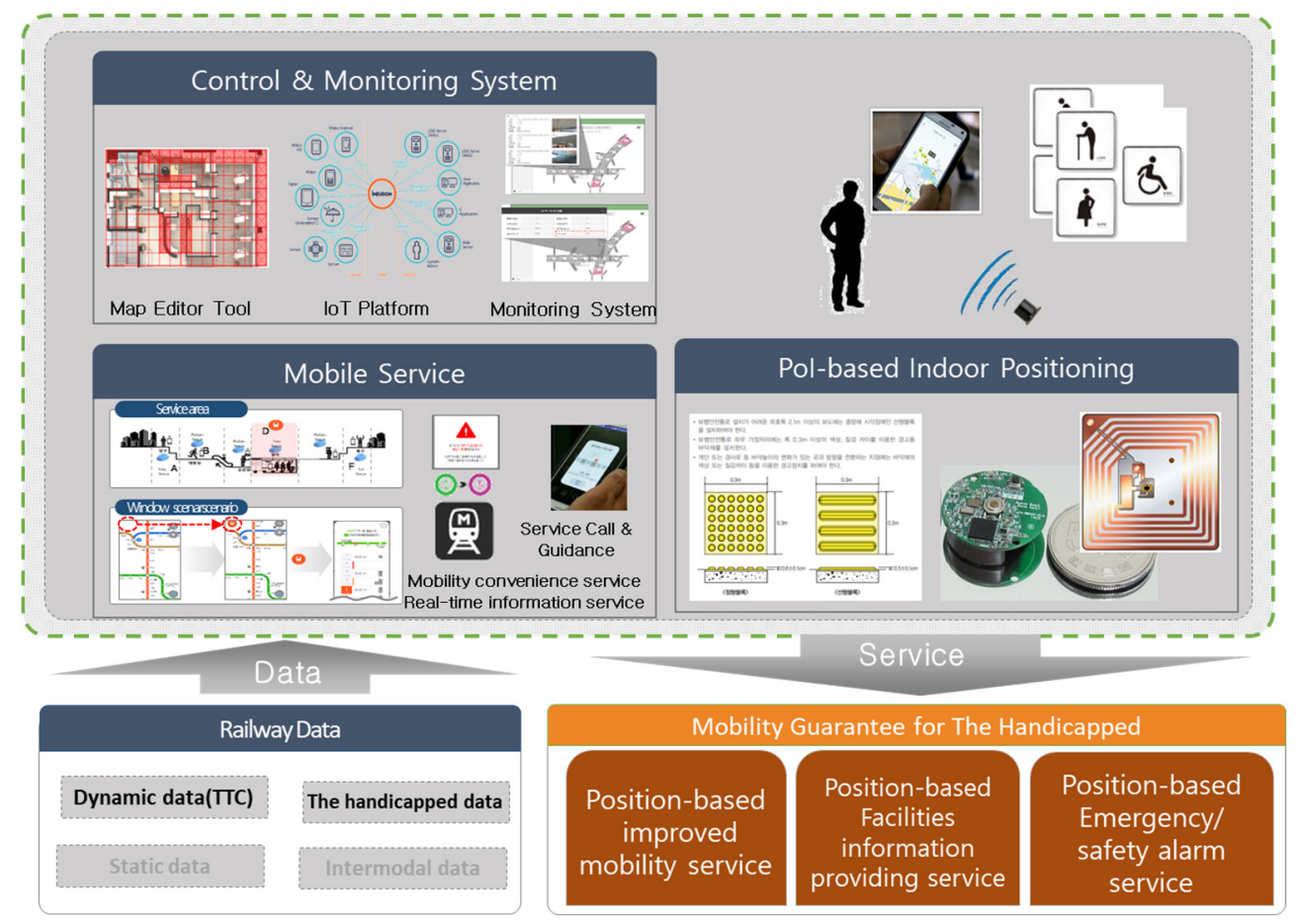

Figure 2: Architecture of the proposed Braille block-based mobile phone application system for guiding the visually impaired through train stations.

\section{DEVELOPMENT OF PROPOSED SYSTEM}

The visually impaired, when at train stations, need a system that can connect with a server anytime and anywhere, to provide convenient route information and facilities location information. This paper proposes the architecture of the system to support the impaired (Fig. 2). This system consists of a monitoring and control system, smart Braille block-based positioning system, and the mobile service via a mobile APP. The detailed architecture and operation mechanism is represented in Hwang et al. [3]. Fig. 2 shows the route guidance and support system for the visually impaired, a system designed to provide the visually impaired with the convenience of mobility and as a traffic welfare service, based on positioning sensors within the station. To support this service, a monitoring and control 
system including a station map generation module, by which the control system can create the optimal convenient path for the impaired to follow using a mobile terminal with the service APP.

Although this system has been basically proposed for the visually impaired, this system was configured to have extendibility, so that even general users or the other mobility handicapped can use it, through generation of dynamic and static data. As shown in Fig. 3, our developed service flows for the visually impaired will be provided on the mobile terminal with a service APP. Basically, this mobile APP is used as a terminal for both the service request and receiving path information. It is designed for the visually impaired and basically provides voice; and also, an additionally standardized user interface/user experience (UI/UX) is provided for the weak-eyed. The developed standardized UI/UX will be verified by its convenient usability, by organizations for the visually impaired.

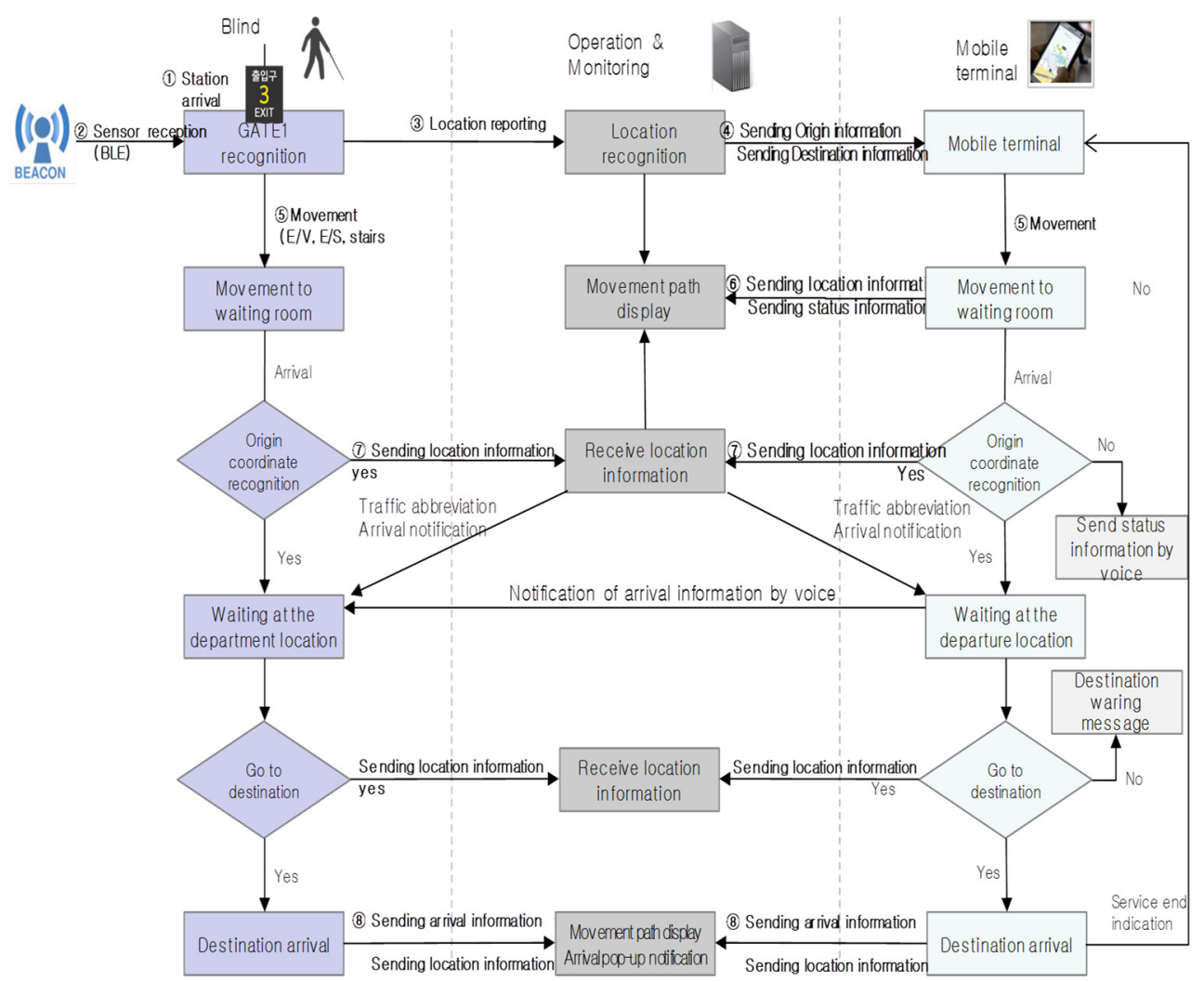

Figure 3: Designed service flow for the visually impaired.

As shown in Fig. 3, the system consists of a mobile APP for a support service, operating and monitoring system, with the visually impaired as a service user. The mobile APP will be requested for services within a station; and then the user will receive feedback on the location and route information, as a result of requests. The operation and monitoring system performs functions such as searching for the optimal travel route for each request and transmitting it 
to the impaired by the mobile APP. Also, the module functions as the location monitor for service users within the station and in station map generating.

As shown in Fig. 3, the operation and monitoring system receives the service request with information on the type of impaired user, their requested destination, and their current location when the impaired person utilizes the service, when approaching or entering the station. And the user will be provided a customized optimal route, as a response to his/her requests. If the impaired user submits the request inside or near the station, the system receives the request through the mobile terminal of the applicant. If the applicant requests help outside the station, the information on the gate to access that station, with stairs or elevators, is provided to the impaired applicant. And when the impaired arrives at the station, that is detected through the BLE sensor installed at the top of the gate, so that the system automatically recognizes that the user has arrived at the station gate. Those functions can be improved to mitigate the navigation dissatisfaction rate without changing the infrastructure.

Upon recognition of arrival at the station, the applicant's mobile phone will be provided with information such as the best route to navigate the destination, the expected arrival time to the destination, and the predicted remaining time, through the mobile APP. And also, the applicant's position is periodically transmitted to the system, so that applicants are monitored in real time for where they are within the station. If the help of station staff is needed for requested services, then a staff member will receive these, and the applicant receives information on the predicted arrival time of helpful staff. The termination process: the service can be automatically terminated when the visually impaired user arrives at the destination point, and can also be terminated by inputting service termination by their mobile phone.

Fig. 4 shows windows for map generation of the service's target station, registering the detailed information of the specific area of the station to the operation and monitoring system. For this proposed service, a digitalized station map is required. For these, a station map generation module was developed. On the right side of Fig. 4, the UI/UX is designed to monitor environmental information such as the number of mobility handicapped people in the specific area of the station, temperature in that area, IoT sensors' indoor locations, etc.

As mentioned above, there are also the weak-eyed, within the visually impaired users. Therefore, the mobile service application is based on the voice interface, but has even been developed to provide information on a simplified application screen. An addition to the impaired user interfaces, such as bone conduction headsets suitable for the visually impaired, are under review. Fig. 5 shows the concept of the impaired using railway station services: the mobile phone provides information via voice or screen, and it guides the appropriate route in the station along the smart Braille block.

The screen has a standard design, so it also works for the weak-eyed. This designed screen will soon be certified for ease of use by a certification authority, in the near future. An example of a screen designed by this system is shown in Fig. 6. As shown in Fig. 6, there are several PoI (Point of Interest) indication screens, route guide screens, and more that are necessary for route guidance. Designed in each railway station, this designed UI was implemented as an APP. The several screens desired are provided to the user along with a sound for information guidance, during the route guidance by mobile phone.

The system we designed and developed was installed and tested in the Busan city hall metro station. For the test, various visually impaired people, from amblyopia to blind, were included (Fig. 7). Then the survey to determine the user satisfaction rate was conducted. The result: the satisfaction rate was significantly improved, as it was 68.7 points before the application of this system, but after use of this system it improved $6.8 \%$, to 73.4 points. 


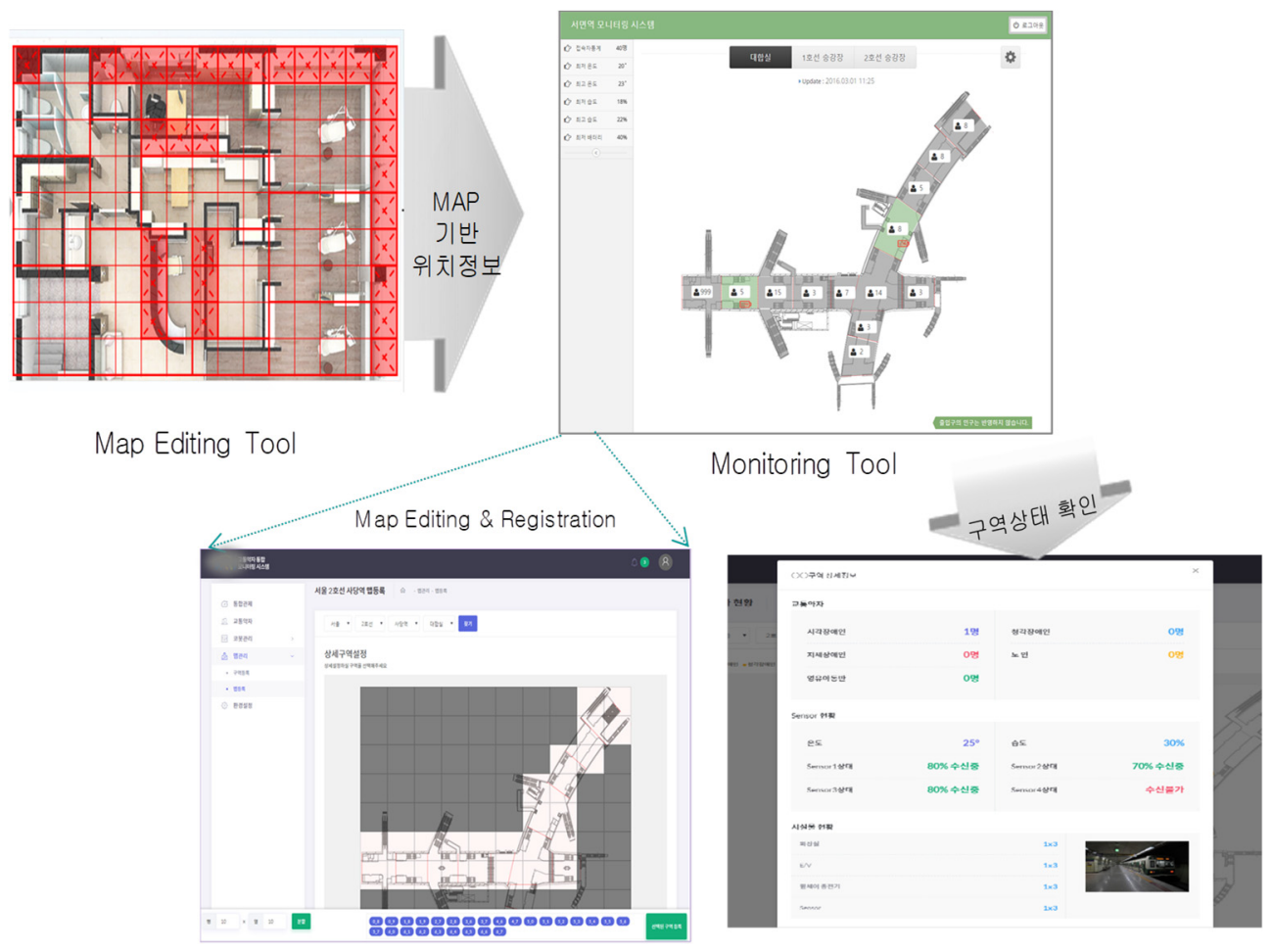

Figure 4: Station map editing tool and identification of other information windows.

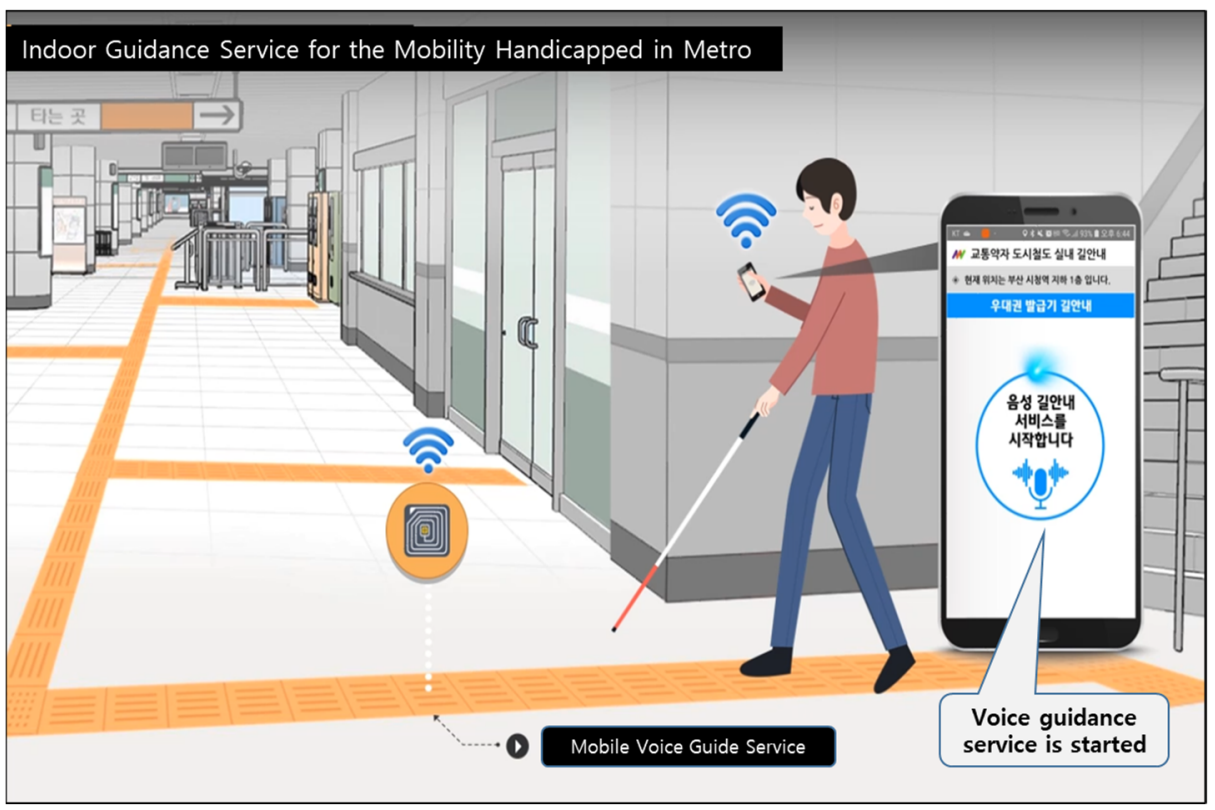

Figure 5: The concept of the impaired using our services. 

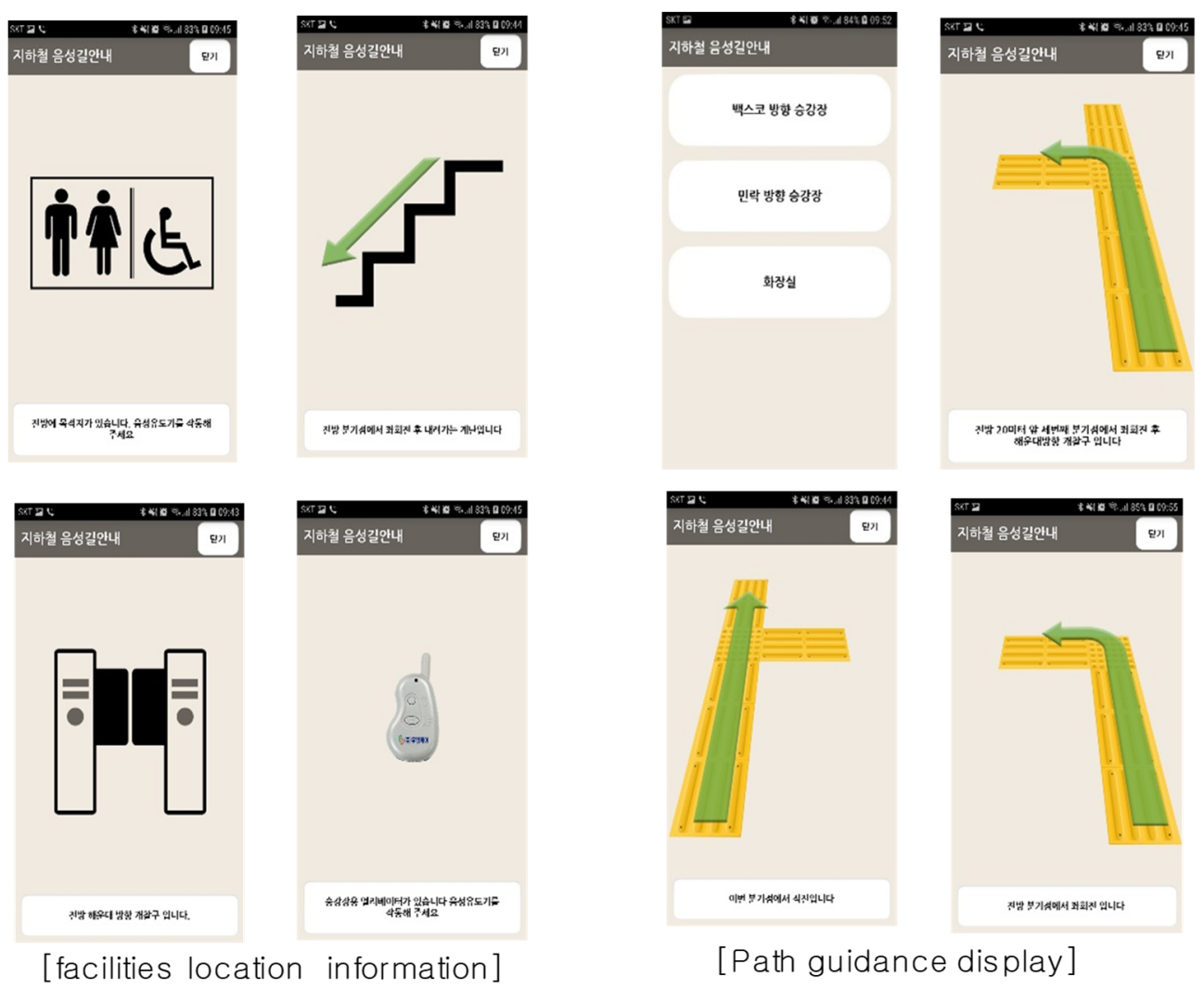

Figure 6: Developed application display for the visually impaired, showing screens for facility location information and the path guidance display.

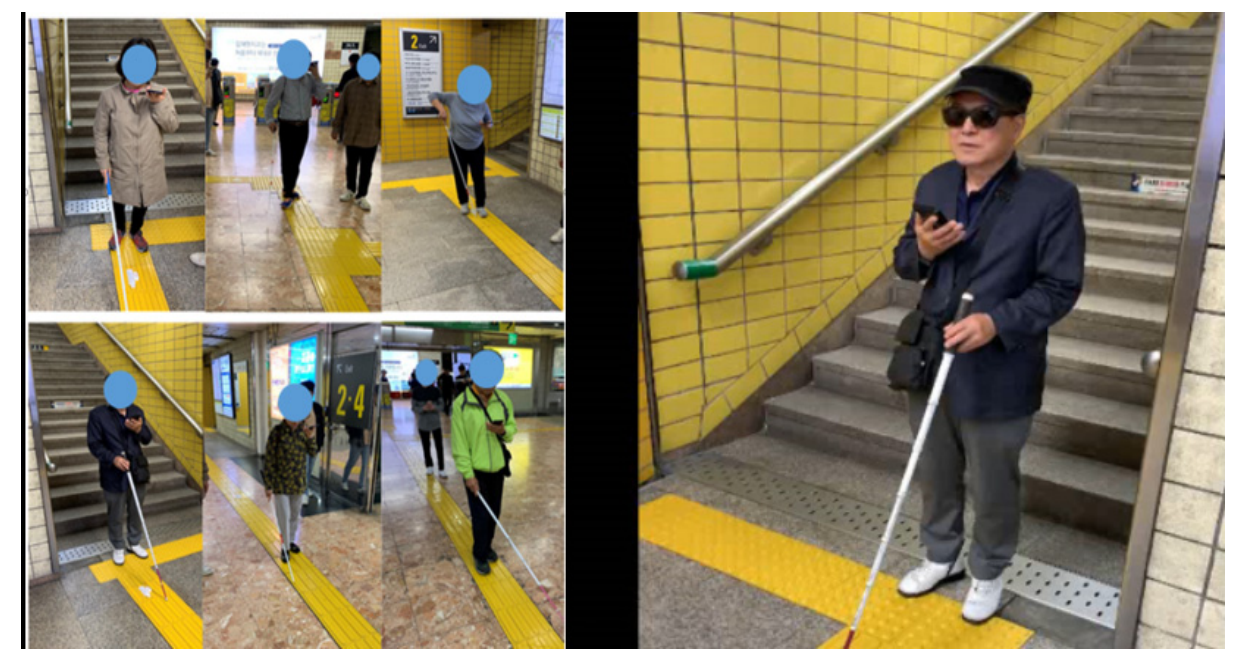

Figure 7: Field testing by the visually impaired. 


\section{CONCLUSION}

For this paper, we first found that the user satisfaction rate was low compared to the installation rate of mobility-supported facilities within the railway station, and that the satisfaction rate of the visually impaired was lower than that of a general user. In addition, we analysed the causes of the low satisfaction rate by the visually impaired: we found out the problems using the railway station. In addition, we proposed a system to improve the satisfaction rate of the visually impaired, through the provision of an enhanced travel convenience by use of a mobile phone with a special APP: a mobile UI design was done for the proposed system. A prototype of the proposed system is being produced and tested in a real metro station. Through this test, we confirmed that the satisfaction rate of the visually impaired was greatly improved, for finding their way within train stations.

\section{REFERENCES}

[1] Korean Act, Mobility Enhancement for the Mobility Handicapped Act.

[2] Ministry of Land, Infrastructure and Transport, In year 2017, a study on the actual condition of movement of the traffic handicapped. Service Report, 2018.

[3] Hwang, J.G. et al., Operational scenario of COBOT for escort of the mobility handicapped at railway station. Proceedings of COMPRAIL, 2018.

[4] Ge, T., Indoor positioning system based on BLE for blind or visually impaired users. Master's thesis, KTH Royal Institute of Technology, 2015.

[5] Co, E.-Y. et al., Requirement of Navigation Service for the Mobility Impaired Person, 2017.

[6] Ryu, K.-S., Lee, S.-H. \& Choim, S.-H., The basic study for the mobility enhancement of mobility handicapped in metro. Proceeding of KSR Spring Conference, 2017. 